\title{
INFLUÊNCIA DA VARIABILIDADE BIOLÓGICA DAS PEÇONHAS NOS ACIDENTES OFÍDICOS
}

\section{ARTIGO DE REVISÃO}

PAIVA, Diego De Assis Moura Rodrigues De ${ }^{1}$

PAIVA, Diego De Assis Moura Rodrigues De. Influência da variabilidade biológica das peçonhas nos acidentes ofídicos. Revista Científica Multidisciplinar Núcleo do Conhecimento. Ano 05, Ed. 07, Vol. 04, pp. 71-88. Julho de 2020. ISSN: 2448-0959, Link de acesso: https://www.nucleodoconhecimento.com.br/biologia/influencia-davariabilidade

\section{RESUMO}

Este trabalho busca demonstrar como a variabilidade biológica dos venenos, sua individualidade química e ação isolada dos compostos, influenciam diretamente nos sintomas dos envenenamentos. Assim sendo, o artigo tem como objetivo principal apresentar uma síntese nos quesitos: venenos ofídicos, composição química, variabilidade biológica e sua influência no quadro clínico dos acidentados. O método de pesquisa científica utilizado foi levantado através de pesquisas bibliográficas nas principais bases de dados, Repitile Data Base, SBH, Google Acadêmico, Scielo, Pubmed, entre os anos de 1979 até 2020. As considerações finais alertam sobre como são significativos os estudos aprofundados a respeito das substâncias animais encontradas e seus respectivos efeitos sob o corpo humano, tendo em vista o esclarecimento de patologias e questões atualmente sem respostas nos campos biológicos.

${ }^{1}$ Especialização em Ecologia e Biodiversidade pelo Instituto Universitário Cândido Mendes (IUCAM/RJ) (2020). Bacharelado em Ciências Biológicas pela Universidade Nove de Julho (2019) e graduação em Gestão Ambiental pela Universidade Nove de Julho (2017). 
Palavras-chave: Variabilidade biológica, venenos animais, acidentes ofídicos, saúde.

\section{INTRODUÇÃO}

Os venenos animais são complexas substâncias que tiveram seu desenvolvimento de acordo com a seleção natural em milhões de anos. Veneno por definição é considerado qualquer substância, preparada ou natural, que por sua atuação química é capaz de destruir ou perturbar as funções vitais de um organismo (STOCKER, 1990).

Suas composições podem variar de acordo com as famílias, grupos, gêneros e espécies. Fatores como isolamento geográfico, dieta, ontogenia, sazonalidade, sexo, hábitos, peculiaridades físicas e fisiológicas podem alterar sua composição química e consequentemente suas ações biológicas (JORGE DA SILVA e AIRD, 2001).

Com o avanço das linhagens, os grupos de serpentes adquiriram órgãos especializados para inoculação e produção de veneno como os Colubridae, Elapidae e Viperidae, gerando assim um interesse maior devido à possibilidade de acidentes com humanos, e futuras descobertas relacionadas à sua complexa peçonha.

As peçonhas ofídicas são formadas por proteoma que envolvem proteínas enzimáticas, como por exemplo, Metaloproteinases, Serinoproteases e Fosfolipases A2 e proteínas não enzimáticas, como, Lectinas do tipo $C$ e Desintegrinas. Além de componentes minoritários como carboidratos, lipídios, aminas biogênicas, nucleotídeos e aminoácidos livres (BIEBER, 1979).

Suas atividades biológicas podem ser divididas em seis tipos, divergindo de acordo com os componentes ativos de sua composição, sendo elas, neurotóxicas, coagulantes, hemorrágicas, miotóxicas e proteolíticas, incluindo ainda atividades inflamatórias devido as bactérias naturalmente presentes na boca dos animais (THORPE et al., 1997; MARK et al., 2008; BERNARDE et al., 2012).

Todos os anos milhares de acidentes por serpentes peçonhentas considerados graves e com relatos de óbitos são notificados em diversas regiões do Brasil e do mundo. 
Com isso, o estudo das peçonhas ofídicas sua fisiologia e composição química são de suma importância para todos os campos da área da saúde, pois, a variabilidade na composição bioquímica e atividade biológica dos venenos podem repercutir na gravidade das manifestações clínicas nos acidentados (SÂMELLA, 2014).

\section{TÍTULO}

\subsection{VENENOS OFÍDICOS}

Os venenos tiveram seu desenvolvimento em aproximadamente 150 milhões de anos e são considerados produtos resultantes de diversas fases evolutivas, revelando assim uma incrível capacidade adaptativa desses animais (Fig.1). São misturas complexas, contendo, entre outros componentes, altas concentrações de proteínas, muitas delas com propriedades tóxicas (STOCKER, 1990).

Os componentes tóxicos podem ter ações rápidas e seletivas muito potentes, capazes de interferir em mecanismos fisiológicos, celulares e moleculares específicos. Cada veneno apresenta uma ação peculiar de cada espécie de serpente, decorrente das classes de toxinas que compõem e do tipo de presa especifica a que é dirigido (JORGE DA SILVA e AIRD, 2001). No entanto, o veneno também pode agir de forma eficaz em outros alvos diferentes da sua dieta (URDANETA et al.,2004).

Os venenos das serpentes contêm aproximadamente $25 \%$ de material sólido, podendo apresentar de padrões incolores até amarelos vibrantes e possuem alta viscosidade (FURTADO et al., 2005). São formados de proteoma apresentando proteínas enzimáticas ou não (aproximadamente $90 \%$ de seu peso seco) e componentes minoritários como aminas biogênicas, carboidratos, nucleotídeos, lipídeos, aminoácidos livres e íons metálicos (BIEBER, 1979).

As proteínas enzimáticas podem ser hidrolases como as proteinases, fosfodiesterases e fosfolipases que auxiliam na digestão do alimento. As fosfolipases clivam a membrana plasmática celular direta ou indiretamente, que é composta de fosfolipídios 
e os converte em subprodutos que geram lise celular (GUTIERREZ e LOMONTE, 1997).

Proteínas com atividade hialuronidásicas estão presentes em todos os venenos de serpentes e são enzimas que facilitam a dispersão dos componentes dos venenos pelos tecidos da presa, atuando nas cadeias do ácido hialurônico que compõe a ligação que mantém as células unidas entre si (FURTADO et al., 2005). Proteinases atuantes no substrato especifico ou não, tais como as serinoproteinases e mataloproteinases. As metaloproteinases são enzimas responsáveis pelos quadros hemorrágicos, edema, dor e necrose dos tecidos, causando, desagregação dos componentes da matriz sub endotelial e podem atuar inibindo a agregação das plaquetas (BJARNASON e FOX,1994; GUTIERREZ e RUCAVADO, 2000).

Serinoproteases são enzimas da família das quimiotripsonas envolvidas nos mecanismos da digestão e processos de degradação proteica, coagulação sanguínea, fibrinólise e ativação do sistema complemento na resposta imune (LESK e FORDHAM, 1996).

Proteínas com atividades enzimáticas são características das peçonhas da família Viperidae (FURTADO et al., 2005). As proteínas não enzimáticas englobam as cardiotoxinas, conhecidas como; citotoxinas, neurotoxinas, miotoxinas, inibidores de proteinases e acetilcolinesterases, apresentando diversas funções farmacológicas, como, hemólise, citotoxidade e despolarização das células musculares (DUFTON e HIDER, 1991; WU, 1998). Estas toxinas são características das peçonhas da família Elapidae (FURTADO et al., 2005). 
Figura 1 - Veneno Bothrops jararacussu.

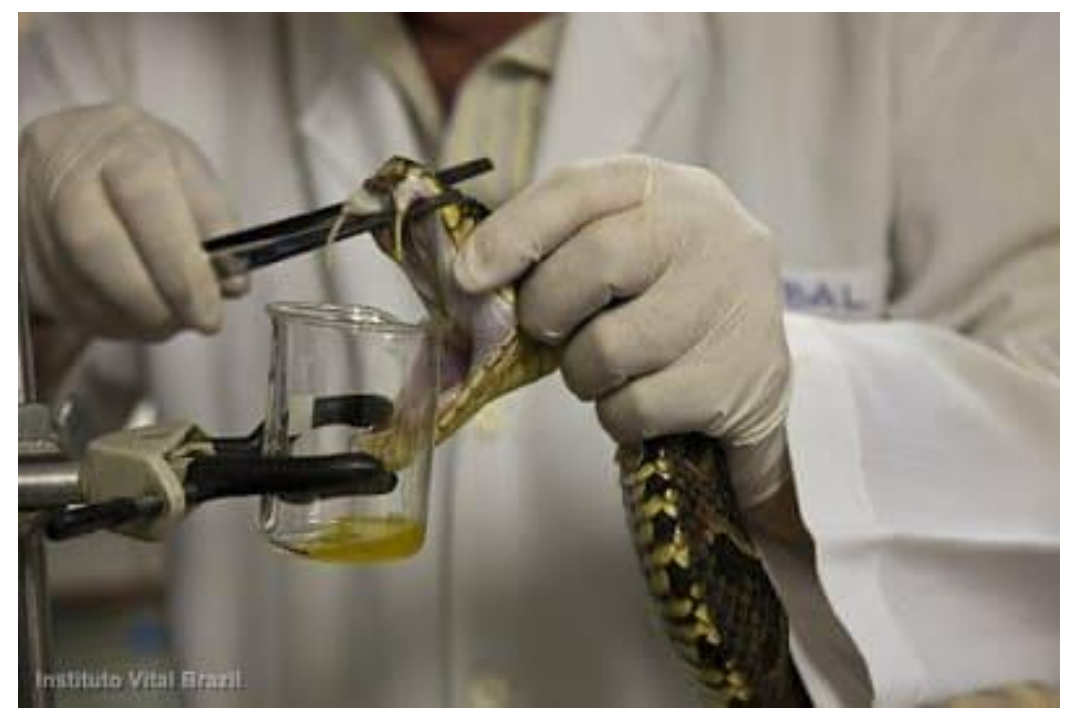

Fonte: INSTITUTO VITAL BRAZIL, 2018.

\subsubsection{VARIABILIDADE BIOLÓGICA DE VENENOS}

Variações na composição química e atividades biológicas dos venenos de serpentes são influenciadas por uma série de fatores, sendo eles, interespecíficos podendo variar entre famílias, gêneros e espécies ou intraespecíficos variando entre sexo, tamanho do animal, dieta, ontogenia e sazonalidade (FURTADO et al., 2005).

Os venenos possuem papeis adaptativos, de acordo com, alimentação (afeta drasticamente sua composição) e defesa. Ocorre seleção natural de propriedades, substâncias e componentes específicos para determinadas presas, como por exemplo, proteínas especializadas para cada ação e/ou propriedades que afetam presas generalizadas. Uma serpente em ambientes mutáveis tem uma pré-disposição para adaptação de sua peçonha. A variabilidade na composição bioquímica e atividades biológicas podem repercutir na gravidade das manifestações clínicas do envenenamento (SÂMELLA, 2014).

O conhecimento destas variações pode fornecer subsídios para terapêutica mais eficaz, auxiliar nos estudos bioquímicos sendo utilizadas como ferramentas 
biotecnológicas para pesquisas, além de auxiliar na caracterização filogenética dos diferentes grupos (CHIPPAUX et al., 1991).

As atividades biológicas dos venenos no mundo podem ser caracterizadas em seis tipos, divergindo de acordo com os componentes ativos na composição das peçonhas animais;

Neurotóxicas: Afetam o sistema nervoso causando inicialmente paralisia dos músculos faciais e mialgia generalizada (dores nos músculos). Em alguns casos ocorre paralisia nos músculos responsáveis pela deglutição e respiração (paralisia dos músculos do diafragma), podendo assim, causar asfixia (insuficiência respiratória) e consequente morte (THORPE et al., 1997; MARK et al., 2008; BERNARDE et al., 2012).

Coagulantes: Aglutinação do sangue, coagulam o fibrinogênio (substância que promove coagulação do sangue), que se deposita em microcoágulos que podem causar obstrução de veias e artérias. O restante do sangue fica incoagulável por falta de fibrinogênio. Casos mais sérios, como os de coágulos cerebrais ou pulmonares, levam à morte (THORPE et al., 1997; MARK et al., 2008; BERNARDE et al., 2012).

Hemorrágicas: Torna os vasos sanguíneos permeáveis ao sangue, causando hemorragias internas e externas, levando ao sangramento das gengivas e narinas. Em quadros mais agravados, as vítimas podem apresentar hemorragias cerebrais e a falência dos rins, levando-as à morte (THORPE et al., 1997; MARK et al., 2008; BERNARDE et al., 2012).

Miotóxicas: Causam danos aos músculos, especialmente aos relacionados à respiração. Por meio de paralisia da função neuromuscular (similar aos efeitos dos venenos neurotóxicos), degrada lipídeos, causando mionecrose, ocorre a liberação de mioglobina (tóxica), e ao ser filtrada pelos rins o envenena. Causa a morte por falência renal e/ou insuficiência renal, cardíaca ou respiratória (THORPE et al., 1997; MARK et al., 2008; BERNARDE et al., 2012). 
Proteolíticas (citotóxicas): Destroem os tecidos levando à necrose, resultado da ação das enzimas digestivas presentes no veneno que degradam as proteínas dos tecidos. Inflamatórias: Alterações locais como dor moderada, inchaço com eritema (vermelhidão), edema local, equimose (sangramento em baixo da pele; "roxidão"), febre, podendo evoluir para uma infecção grave e levar a morte (THORPE et al., 1997; MARK et al., 2008; BERNARDE et al., 2012).

Hemolíticas: Causa destruição das células vermelhas do sangue, se expressa sob a forma de hemoglobinúria (urinar sangue). Pode causar insuficiência renal aguda, principal causa de óbito (THORPE et al., 1997; MARK et al., 2008; BERNARDE et al., 2012).

As atividades biológicas das peçonhas nas serpentes com interesse em saúde no Brasil podem ser expressas com diferentes mecanismos de ação, conforme mostra a tabela (Tabela I).

Tabela I - Atividades biológicas das peçonhas no Brasil

\begin{tabular}{|l|l|l|l|l|l|l|}
\hline $\begin{array}{l}\text { FAMÍL } \\
\text { IAS }\end{array}$ & $\begin{array}{l}\text { GÊNE } \\
\text { ROS }\end{array}$ & \multicolumn{2}{|l|}{ ATIVIDADES BIOLÓGICAS } \\
& $\begin{array}{l}\text { NEUROTÓ } \\
\text { XICA }\end{array}$ & $\begin{array}{l}\text { MIOTÓX } \\
\text { ICA }\end{array}$ & $\begin{array}{l}\text { COAGUL } \\
\text { ANTE }\end{array}$ & $\begin{array}{l}\text { PROTEOLI } \\
\text { TICA }\end{array}$ & $\begin{array}{l}\text { HEMORRÁ } \\
\text { GICA }\end{array}$ \\
\hline $\begin{array}{l}\text { Víperid } \\
\text { ae }\end{array}$ & $\begin{array}{l}\text { Bothro } \\
\text { ps }\end{array}$ & - & - & sim & sim & sim \\
\hline & $\begin{array}{l}\text { Crotalu } \\
\text { s }\end{array}$ & sim & sim & sim & - & - \\
\hline & $\begin{array}{l}\text { Laches } \\
\text { is }\end{array}$ & sim & - & sim & sim & sim \\
\hline $\begin{array}{l}\text { Elapid } \\
\text { ae }\end{array}$ & $\begin{array}{l}\text { Micrur } \\
\text { us }\end{array}$ & sim & sim & - & - & - \\
\hline
\end{tabular}

Fonte: PAIVA, 2020. 


\section{ACIDENTES OFÍDICOS}

De acordo com o Ministério da saúde, acidente ofídico ou ofidismo é o quadro de envenenamento decorrente da inoculação de uma peçonha através do aparelho inoculador especializado (presas) de serpentes. No Brasil, segundo dados do mesmo, ocorrem entre 19 mil a 22 mil acidentes ofídicos por ano.

As serpentes peçonhentas de interesse em saúde pública pertencem às Famílias Viperidae (OPPELL, 1811) e Elapidae (BOIE, 1827). Os acidentes são divididos em quatro diferentes tipos, pois, a variabilidade na composição bioquímica e atividade biológica dos venenos podem repercutir na gravidade das manifestações clínicas. (SÂMELLA, 2014).

Acidentes Botrópicos ocorrem com serpentes dos gêneros Bothrops e Bothrocophias que compreendem o grupo das jararacas. Crotálicos com serpentes do gênero Crotalus, as conhecidas cascavéis. Laquéticos, acidentes com serpentes do gênero Lachesis, as surucucus, e por fim acidentes Elapídicos englobando serpentes dos gêneros Micrurus e Leptomicrurus, as corais verdadeiras (MINISTÉRIO DA SAÚDE, 2017).

A frequência de acidentes está distribuída de maneira não homogênea, estando relacionada com a distribuição geográfica populacional e abundância de animais de determinadas espécies. Atualmente, de acordo com a Portaria 993/GM/MS de 4/9/2000, os acidentes causados por animais peçonhentos não estão mais incluídos na lista de doenças e agravos à saúde de notificação compulsória (ARAÚJO, SANTALÚCIA e CABRAL, 2003), e os dados estatísticos encontram-se fragmentados por serem informados por mais de uma entidade (SANDRIN e PUORTO, 2005).

A falta de informação dos acidentados, descaso no informe de acidentes por órgãos responsáveis e o despreparo dos médicos deixam lacunas no número real envolvendo esses animais no Brasil, sendo assim; acidentes Botrópicos 75\%, Crotálicos 7\%, Laquéticos $3 \%$, Elapídicos $1 \%$, não peçonhentos $4 \%$ e brancos aproximadamente $12 \%$ (Gráfico I). 
Gráfico I - Percentual dos acidentes ofídicos brasileiros.

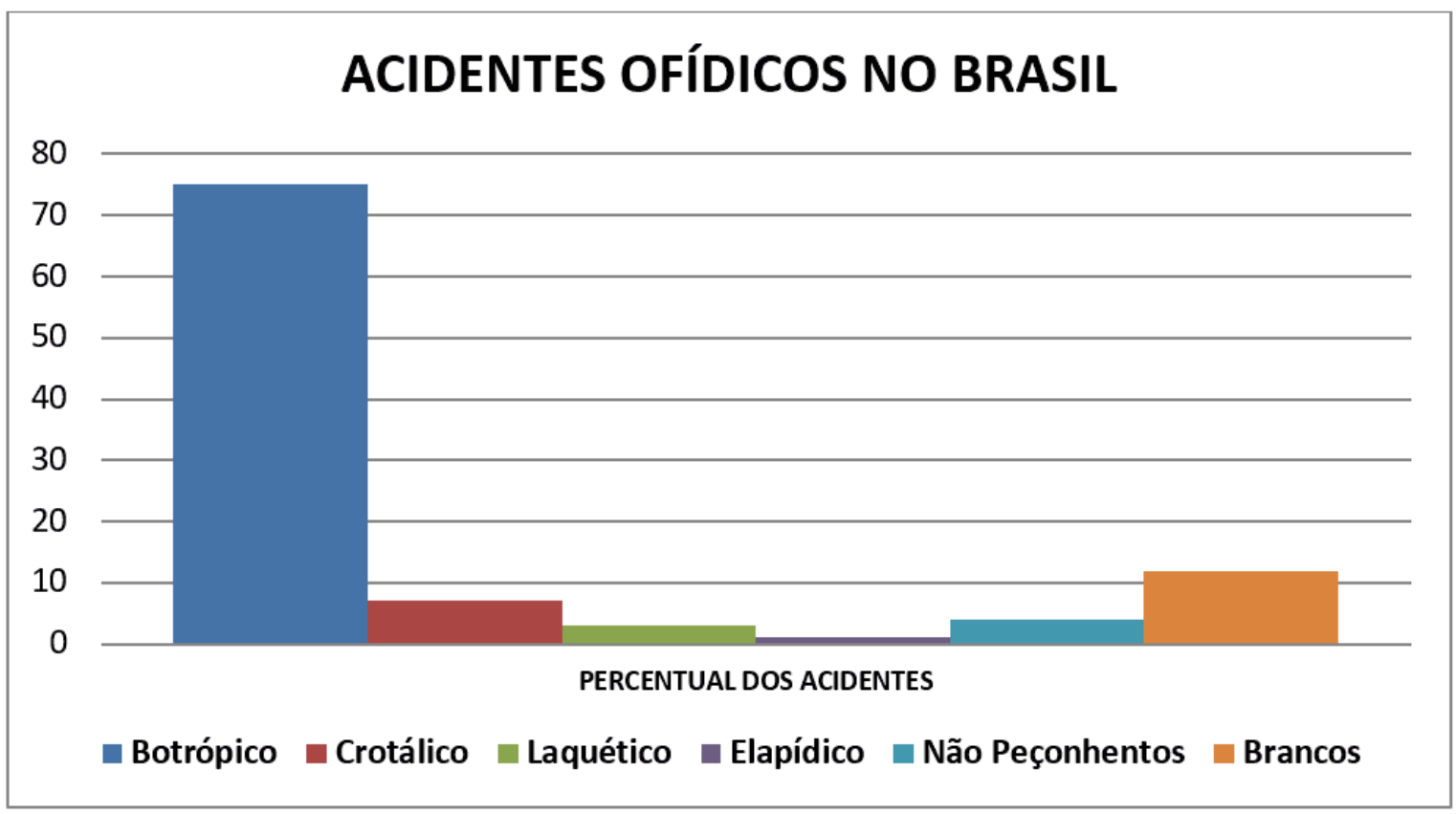

Fonte: PAIVA, 2020.

O tratamento é realizado com o soro específico para cada tipo de envenenamento. Os soros antiofídicos específicos são o único tratamento eficaz e, quando indicados, devem ser administrados em ambiente hospitalar e sob supervisão médica (MINISTÉRIO DA SAÚDE, 2017).

- Acidente Botrópico (Atividades coagulantes, proteolíticas e hemorrágicas)

Manifestações locais, como, dor e edema endurado no local da picada, de intensidade variável, geralmente de instalação precoce e caráter progressivo. Equimoses e sangramentos no ponto da picada são frequentes. Infartamento ganglionar e bolhas podem aparecer acompanhadas ou não de necrose (Fig. 2).

Nas manifestações sistêmicas podem surgir sangramentos em ferimentos préexistentes e são observadas hemorragias à distância como gengivorragias, epistaxes, hematêmese e hematúria. Em gestantes, há risco de hemorragia uterina. 
Podem ocorrer náuseas, vômitos, sudorese, hipotensão arterial, hipotermia e mais raramente, choque. Nos acidentes causados por filhotes de Bothrops predominam as alterações de coagulação; dor e edema locais podem estar ausentes (SECRETÁRIA DE SAÚDE DO PARANÁ, 2019).

Figura 2 - Acidente causado por Bothrops jararacussu, necrose local de membro inferior.

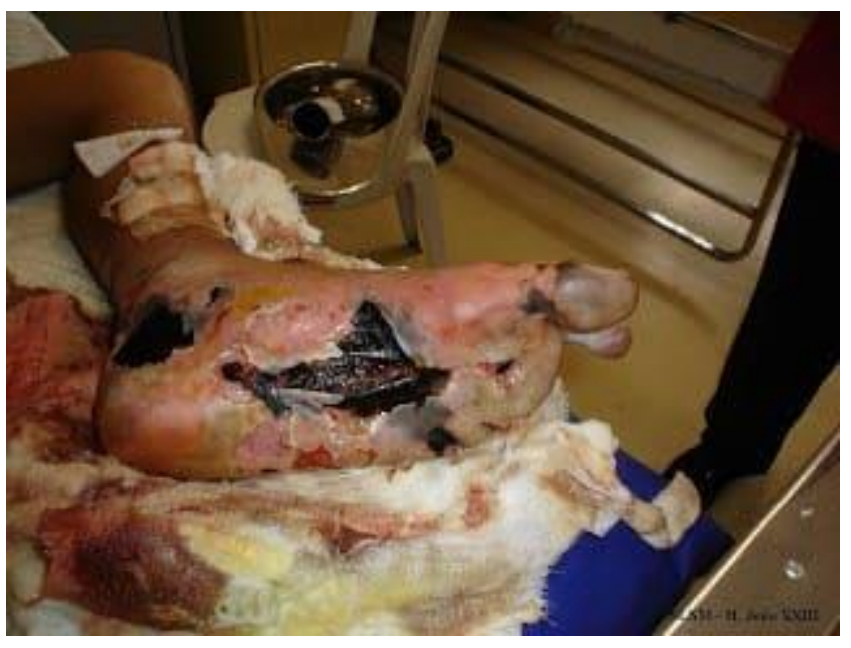

Fonte: LACHESIS BRASIL, 2013.

- Acidente Crotálico (Atividades neurotóxicas, miotóxicas e coagulantes)

Em relação às manifestações locais podem ser encontradas as marcas das presas, edema e eritema discretos. Não há dor, ou se existe, é de pequena intensidade. Há parestesia local ou regional, podendo ser acompanhada de edema discreto ou eritema no ponto da picada.

As manifestações sistêmicas gerais podem englobar; mal-estar, sudorese, náuseas, vômitos, cefaléia, secura da boca, prostração e sonolência ou inquietação.

Manifestações neurológicas, decorrentes da ação neurotóxica do veneno, apresentam-se nas primeiras horas e caracterizam a "fáscie miastênica" (fáscie neurotóxica de Rosenfeld) evidenciadas por ptose palpebral uni ou bilateral, que é uma flacidez da musculatura da face, há oftalmoplegia e dificuldade de acomodação 
(visão turva) e/ou visão dupla (diplopia), além de, alteração do diâmetro pupilar (midríase). Com menor frequência pode aparecer paralisia velopalatina, com dificuldade de deglutição, diminuição do reflexo do vômito, modificações no olfato e no paladar.

Manifestações musculares, decorrentes da atividade miotóxica, caracterizam-se por dores musculares generalizadas (mialgias).

A urina pode estar clara nas primeiras horas e assim permanecer, ou tornar-se avermelhada (mioglobinúria) e progressivamente marrom nas horas subsequentes, traduzindo a eliminação de quantidades variáveis de mioglobina, pigmento liberado pela necrose do tecido muscular esquelético (rabdomiólise) (Fig.3).

Pode haver aumento do Tempo de Coagulação (TC) ou incoagulabilidade sanguínea, com queda do fibrinogênio plasmático, em aproximadamente $40 \%$ dos pacientes. Raramente há pequenos sangramentos, geralmente restritos às gengivas (gengivorragia).

Manifestações Clínicas pouco frequentes como; insuficiência respiratória aguda, fasciculações e paralisia de grupos musculares têm sido relatadas e interpretadas como decorrentes das atividades neurotóxicas e miotóxicas do veneno, de acordo com a Secretaria de Saúde do Paraná, 2019.

Figura 3 - Acidente causado por Crotalus durissus, urina sequencial coletada em $48 \mathrm{~h}$ após acidente, diurese escurecida com mioglobinúria.

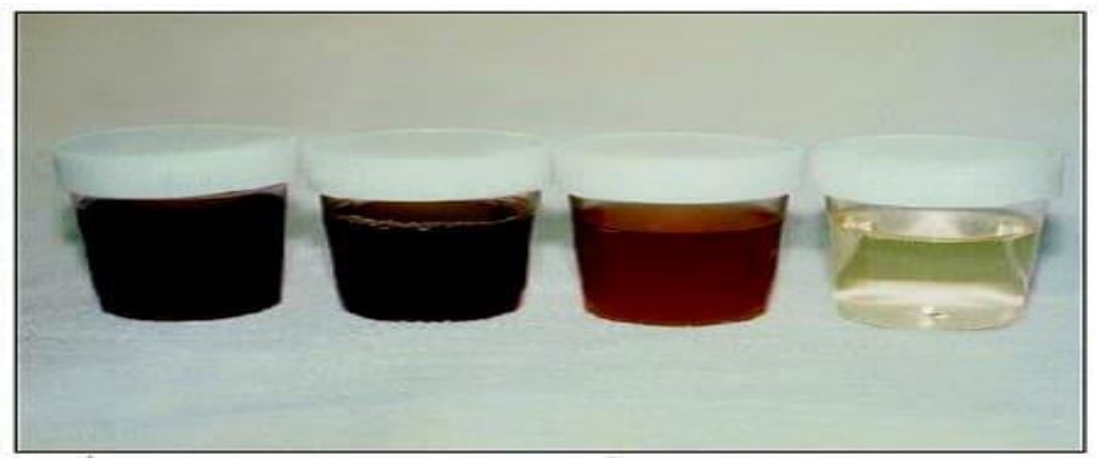

Fonte: F. BUCARETCHI, 2014 
- Acidente Laquético (Atividades coagulantes, proteolíticas, hemorrágicas e neurotóxicas)

Semelhantes às do acidente botrópico, predominando dor e edema. Podem surgir vesículas de conteúdo seroso ou sero-hemorrágico nas primeiras horas do acidente. Manifestações hemorrágicas, na maioria dos casos no local da picada (Fig.4). Manifestações sistêmicas como hipotensão arterial, tonturas, escurecimento da visão, bradicardia, cólicas abdominais e diarreia ("síndrome vagal") podem aparecer, segundo dados da Secretaria de Saúde do Paraná, 2019.

Figura 4 - Acidente causado por Lachesis muta, necrose extensa de membro inferior.

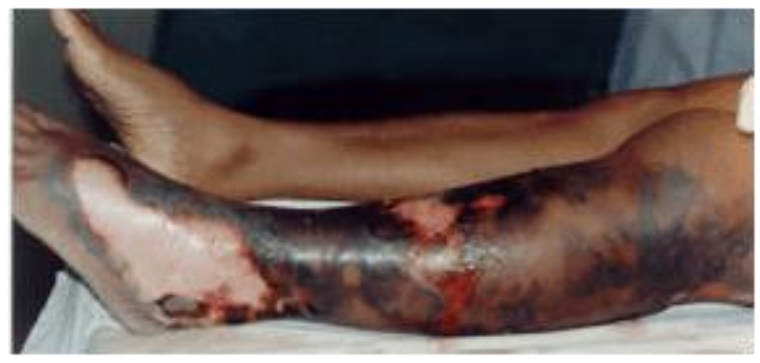

Fonte: HOSPITAL VITAL BRAZIL, 2019

- Acidente Elapidico (Atividades neurotóxicas e miotóxicas)

Manifestações semelhantes aos acidentes Laquéticos, com exceção dos edemas locais, como por exemplo, dor local e discreta (muitas vezes ausente) acompanhada de parestesia de progressão proximal. Manifestações Sistêmicas, inicialmente vômitos, posteriormente fraqueza muscular progressiva, ptose palpebral, sonolência, perda de equilíbrio, sialorréia, oftalmoplegia e presença de fáscies miastênica (Fig.5). Podem surgir mialgias localizadas ou generalizadas, dificuldade de deglutir e afonia, devido à paralisia do véu palatino. $\mathrm{O}$ quadro de paralisia flácida pode comprometer a musculatura respiratória, evoluindo para apneia e insuficiência respiratória aguda (esta considerada uma complicação do acidente) (SECRETARIA DE SAÚDE DO PARANÁ, 2019). 
Figura 5 - Acidente causado por Micrurus frontalis, ptose palpebral bilateral (fáscie miastênica).

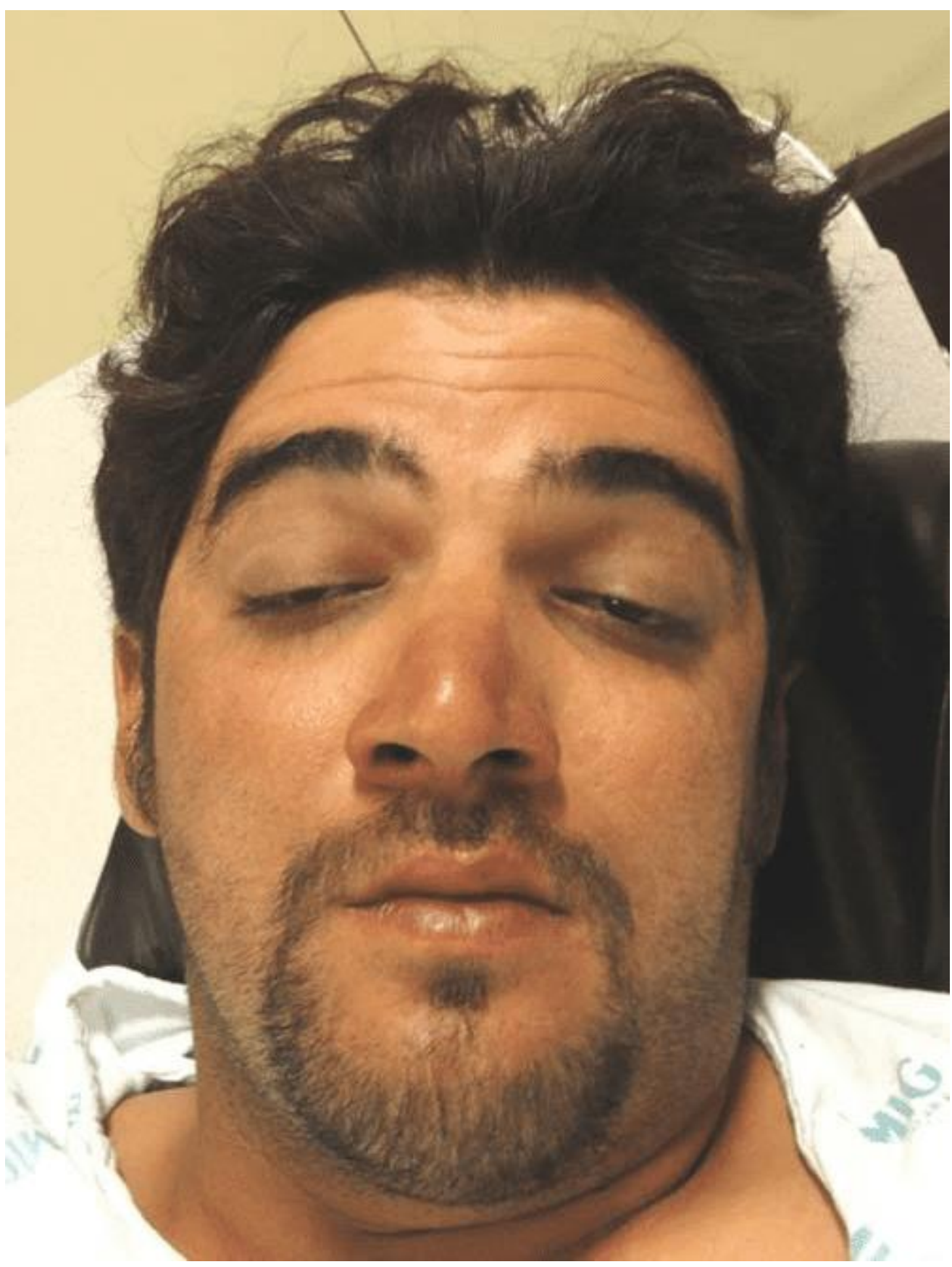

Fonte: UNIVERSIDADE FEDERAL DE MINAS GERAIS, 2019 


\section{CONSIDERAÇÕES FINAIS}

Mesmo com avanços generalistas em relação aos tratamentos, sua funcionalidade sob ações especificas dos venenos ainda é inexistente, e além do mais, a falta de iniciativa de entidades agrava a situação.

Os acidentes ofídicos, assim como a leishmaniose, a doença de Chagas, a febre amarela, entre outras, são doenças classificadas pela Organização Mundial da Saúde como Doenças Tropicais Negligenciadas, um grupo de doenças que acometem principalmente países tropicais em desenvolvimento. Apesar do grande número de casos todos os anos, não há interesse da indústria farmacêutica para o desenvolvimento de novos fármacos por conta das vítimas estarem afastadas dos grandes mercados consumidores.

As picadas de serpentes peçonhentas atingem cerca de um milhão de pessoas por ano no mundo, com cerca de 300 mil mortes. No Brasil, o número chega a 20 mil por ano, mas o total de mortes é relativamente baixo (150) por conta das características das peçonhas.

Portanto, considerando que o país é uma das maiores fontes biotecnológicas existentes, verificam-se a importância da proximidade dos diferentes campos científicos para estudos aprofundados a respeito das substâncias animais encontradas, tendo em vista o esclarecimento de patologias e questões atualmente sem respostas nos campos biológicos.

\section{REFERÊNCIAS}

AGUIAR, A.S.; ALVES, C.R.; MELGAREJO, A.R. \& GIOVANNI-DE-SIMONE, S. Purification and partial characterization of a thrombinlike/ gyroxin enzyme from bushmaster (Lachesis muta rhombeata) venom. Toxicon, v. 34: 555-565. 1996.

AMARAL, C. F. S.; ARAÚJO, F. A. A.; BUCARETCHI, F. Manual de diagnóstico e tratamento de acidentes por animais peçonhentos, Brasilia, 2001.120 p. 
ANDRADE, D.V. \& ABE, A.S. Relationships of venom ontogeny and diet in Bothrops. Herpetologica, v.55: 200-204. 1999.

ARAÚJO, F.A.A.; SANTALÚCIA, M.; CABRAL, R.F. Epidemiologia dos acidentes por animais peçonhentos. In: CARDOSO, J.L.C. et al. Animais peçonhentos no Brasil. Biologia, clínica e terapêutica dos acidentes. São Paulo: Sarvier, FAPESP, 2003, p.6-12.

AUGUSTO; SOUZA; GONZALES. Aplicação Terapêutica das Toxinas de Ofídios Peçonhentos Encontrados em Território Brasileiro, São Paulo: Centro Universitário Lusíada, 2015. 1 p.

AZEVEDO-MARQUES M.M., HERING S .E., CUPO, P. Acidente crotálico. In: Animais peçonhentos no Brasil. Biologia, clínica e terapêutica dos acidentes. 2009. Sarvier, São Paulo. $2^{\mathrm{a}}$ edição.

BENEDITO BARRAVIERA. Isolamento de serino-proteases coagulantes dos venenos de Bothrops neuwiedi pauloensis e Crotalus durissus terrificus: caracterização funcional e estrutural, Botucatu: Universidade Estadual de São Paulo, 2009.

BIEBER, A.L. Metal and nonprotein constituents in snake venoms. In: LEE, C.Y. (org.) Handbook of experimental pharmacology, v.52. Snake venoms. Berlin: SpringerVerlag, 1979. cap.9, v.1, p.295-306.

BIOLOGIA ETERNA. FOTOS DE ACIDENTES OFÍDICOS. Disponível em:(http://biologiaeterna.blogspot.com/2011/04/fotos-de-acidentes-ofidicos.html). Visualizado em 19/04/2020.

BJARNASON, J.B. \& FOX, J.W. Hemorrhagic metalloproteinases from snake venoms. Pharmacological Therapeutic, v.62: 325-372. 1994. 
CARDOSO, J. L. C.; FRANÇA, F. O. S.; FAN, H.; MALAQUE, C. M. S.; HADDAS JR., V. Animais Peçonhentos no Brasil - Biologia, Clinica e Terapêutica dos Acidentes 2 ed., São Paulo: Sarvier, 2009. 540 p.

CARVALHO DOS SANTOS; LATORRE, M. C. DOS SANTOS. Aplicações farmacológicas dos venenos de serpentes brasileiras enfoque para Crotalus durissus terrificus e Crotalus durissus ruruima, Amazonas: Universidade Federal do Amazonas, 2017. $12 \mathrm{p}$.

CASARETT; DOULL. Fundamentos em toxicologia 2 ed, São Paulo: Lange, 2012. $472 \mathrm{p}$.

CHIPPAUX, J. P.; WILLIAMS, V.; WHITE, J. Snake venom variability: methods of study, results and interpretation. Toxicon., 29(11): 1279-303, 1991.

COTTA, G. A. Animais peçonhentos 5 ed., Belo Horizonte: Funed, 2014. 24 p.

CUNHA, E. M.; MARTINS, O. A. Principais compostos químicos presente nos venenos de cobras dos gêneros bothrops e crotalus - uma revisão vol 2, São Paulo: Reec, 2012. 6 p.

DUFTON, M.J. \& HIDER, R.C. The structure and pharmacology of Elapid cytotoxins. In: HARVEY, A.L. (ed.) Snake Toxins. Pergamon Press, New York, 1991. p.259-302.

FREITAS, M. A. Serpentes Brasileiras, Bahia: Instituto Chico Mendes, 2003. 81 p.

FURTADO, M. F. D.; MUNIZ. Aspectos Sistemáticos e Biológicos que atuam na diversidade da composição de venenos em serpentes peçonhentas brasileiras, São Paulo, 2005. 18 p. Dissertação (Mestrado) - Programa de pós-graduação Universidade de São Paulo, 2005.

GUTIÉRREZ, J.M. \& LOMONTE, B. Phospholipase A myotoxins from Bothrops snake 2 venoms. In: KINI, R.M. (ed.) Venom phospholipase A enzymes. Structure, function and mechanism. 2 Wiley, Chichester, 1997. p.321-352. 
GUTIÉRREZ, J.M. \& RUCAVADO, A. Snake venom metalloproteinases: their role in the pathogenesis of local tissue damage. Biochimie, v.82: 841-850. 2000.

HUANCAHUIRE; MARANGONI. Isolamento de duas Toxinas do Veneno da Serpente Bothrops brazili, Campinas: Universidade de Campinas, 2014. 1 p.

INSTITUTO BUTANTAN. Produção de Soros e Vacinas. Disponível em: (http://www.butantan.gov.br). Visualizado em 03/04/2019.

INSTITUTO VITAL BRAZIL. Acidentes Ofídicos. Disponível em: (http://www.vitalbrazil.rj.gov.br). Visualizado em 03/04/2019.

JORGE-DA-SILVA, N. \& AIRD, S.D. Prey specificity, comparative lethality and compositional differences of coral snake venoms. Comparative Biochemistry and Physiology Part C, v.128: 425- 456. 2001.

LACHESIS BRASIL. PRIMEIROS SOCORROS AOS ACIDENTADOS POR ALGUNS DOS ANIMAIS PEÇONHENTOS MAIS COMNUS DO BRASIL. Disponível em: (http://lachesisbrasil.blogspot.com/2013/08/primeiros-socorros-aos-acidentadospor.html). Visualizado em 19/04/2020.

LESK, A.M. \& FORDHAM, W.D. Conservation and variability in the structures of serine proteinases of the chymotrypsin family. Journal Molecular Biology, v.258: 501-537. 1996.

MARK O'SHEA, 2008, Venomous Snakes of the World. MATTOS FONTES. Estudos estruturais com toxinas de venenos de serpentes, Botucatu: Universidade Estadual de São Paulo, 2017. 4 p.

MEREGALLI, B.; MOREIRA, J. M. S.; FERRI, M. Veneno de Bothrops jararaca na Utilização de Medicamentos para Hipertensão vol 4, Osório: Facos, 2013. 2 p.

MINISTÉRIO DA SAÚDE. ACIDENTES POR ANIMAIS PEÇONHENTOSSERPENTES. Disponível em: (https://www.saude.gov.br/saude-de-a-z/acidentes-poranimais-peconhentos-serpentes). Visualizado em 19/04/2020. 
MINISTÉRIO DA SAÚDE. Manual de diagnóstico e tratamento de acidentes por animais peçonhentos, Fundação Nacional de Saúde/Coordenação de Controle de Zoonoses e Animais Peçonhentos. Brasília: CENEPI, p.131. 1998.

MOREIRA, K. G. Estudo dos componentes protéicos da peçonha da serpente Micrurus frontalis (serpentes: Elapidae), Brasilia, 2010. 136 p. Dissertação (Doutorado) - Programa de pós-graduação em Biologia Animal - Universidade de Brasilia, 2010.

NASCIMENTO, L. B.; OLIVEIRA, M. E. Herpetologia no Brasil 2 ed., Belo Horizonte: $\mathrm{SBH}, 2007.354 \mathrm{p}$.

PÁDUA, A.; SIFUENTES, D.; WEN, F. H. Guia brasileiro de vigilância epidemiológica 7 ed., Brasilia: Ministério da Saúde, 2009. 813 p.

PAULO SÉRGIO BERNARDE, SAYMON DE ALBURQUERQUE, LUIZ CARLOS BATISTA TURCI, 2012 , Serpentes Peçonhentas e Acidentes Ofídicos em Rondônia.

PINHO, F. M. O.; PEREIRA I. D. Ofidismo - Revisão, Goiânia: Faculdade Federal de Goiás, 2001. 6 p.

RAIMUNDO NONATO LEITE PINTO, NELSON JORDE DA SILVA, STEVEN D. AIRD. Human Envenomation by the South American Opisthoglyph Clelia clelia plumbea (WIED). Toxicon. Volume 29, Issue 12, 1991, Pages 1512-1516.

SAMÊLLA, S.; IDA S. Atividades Biológicas do Veneno de Bothrops atrox Capturadas na Floaresta Nacional do Tapajós, Oeste do Pará, São Paulo: Dissertação apresentada ao Programa de Pós-Graduação em Toxinologia do Instituto Butantan para obtenção do título de Mestre em Toxinologia, 2014. 83p.

SANDRIN, M. F. N.; PUORTO, G. Serpentes e acidentes ofídicos: Um estudo sobre erros conceituais em livros didáticos, São Paulo: Investigação em ensino de ciências (UNESP), 2005. 18 p. 
SANTOS, M. C. Serpentes de Interesse Médico da Amazônia - Biologia, venenos e tratamento de acidentes, Manaus: Universidade do Amazonas, 1995. 70 p.

SECRETARIA DE ESTADO DA SAÚdE DE SÃo PAULO. Ataques de Animais Peçonhentos Dobram em 10 Anos no Estado. Disponível em:(http://www.saude.sp.gov.br/ses/noticias/2011/marco/ataques-de-animaispeconhentos-dobram-em-10-anos-no-estado). Visualizado em 19/04/2020

SECRETÁRIA DE ESTADO DA SAÚdE. Animais Peçonhentos. Disponível em (http://www.cve.saude.sp.gov.br). Visualizado em 10/05/2019.

SECRETARIA DE SAÚDE DO PARANÁ. ACIDENTES POR ANIMAIS PEÇONHENTOS.

em:(http://www.saude.pr.gov.br/arquivos/File/zoonoses_intoxicacoes/Acidentes_por_ Animais_Peconhentos_e_Venenosos.pdf). Visualizado em 19/04/2020.

SOCIEDADE BRASILEIRA DE HERPETOLOGIA. Serpentes do Brasil. Disponível em (http://sbherpetologia.org.br). Visualizado em 25/03/2019.

SOUZA, L.F.. ; ZDENEK, C. N. ; DOBSON, J. S. ; BROUW, B. O. D. ; COIMBRA, F. ; GILLETT, A. ; Del Rei, T. H. M. ; CHALKIDIS, H. M. ; SANTANNA, S. S. ; ROCHA, M. M. T. ; GREGO, K. ; TRAVAGLIA CARDOSO, SILVIA REGINA ; MOURA DA SILVA, A. M. ; FRY, B. G. . Coagulotoxicity of Bothrops (Lancehead Pit-Vipers) Venoms from Brazil: Differential Biochemistry and Antivenom Efficacy Resulting from Prey-Driven Venom Variation vol 10, São Paulo: Toxins, 2018. 26 p.

STEVEN D. AIRD, NELSON JORGE DA SILVA JR. Comparative Enzymatic Composition of Brazilian Coral Snake (Micrurus) Venoms. Comparative Biochemistry and Physiology Part B: Comparative Biochemistry, Volume 99, Issue 2, 1991, Pages 287-294.

STOCKER, K.F., 1990. Composition of Snake Venom. In: Medical Use of Snake Venom Proteins. Stocker, K. F., CRC Press, Florida. 33-57. 
THORPE R. S., W WUSTER AND A. Malthora (eds.), 1997, Venomouns Snakes: Ecology, Evolution and Snikebite. Zoological Society of London.

UNIVERSIDADE FEDERAL DE MINAS GERAIS. Ofidismo. Disponível em (https://www.medicina.ufmg.br). Visualizado em 22/02/2019.

URDANETA, A.H.; BOLAÑOS, F. \& GUTIÉRREZ, J.M. Feeding behavior and venom toxicity of coral snake Micrurus nigrocinctus (Serpentes: Elapidae) on its natural prey in captivity. Comparative Biochemistry and Physiology, Part C, v.138 485-492. 2004.

WU, W. Cobra cardiotoxin and phospholipase A as 2 GAG-binding toxins. On the path from structure to cardiotoxicity and inflammation. Trends in Cardiovascular Medicine, v.8: 270-278. 1998.

Enviado: Maio, 2020.

Aprovado: Julho, 2020. 